\title{
Concerning the FERMO Concept and Pearson's Hard and Soft Acid-Base Principle
}

\author{
Rodrigo R. da Silva, ${ }^{a}$ Joana M. Santos, ${ }^{b}$ Teodorico C. Ramalho ${ }^{c}$ and J. Daniel Figueroa-Villar, ${ }^{* a}$ \\ ${ }^{a}$ Departamento de Química, Instituto Militar de Engenharia, Praça General Tibúrcio, 80, 22290-070 \\ Rio de Janeiro-RJ, Brazil \\ ${ }^{b}$ Departamento de Química Geral e Inorgânica, Instituto de Química, Universidade do Estado do Rio de Janeiro, \\ Rua São Francisco Xavier, 524, 20550-013 Rio de Janeiro-RJ, Brazil

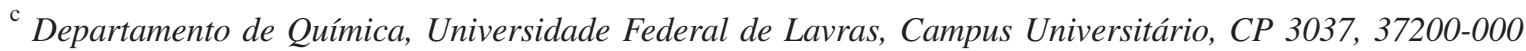 \\ Lavras-MG, Brazil
}

\begin{abstract}
O conceito FERMO foi empregado com sucesso ao princípio ácido-base de dureza e moleza de Pearson para quatro ligantes ambidentados. Usando um postulado intuitivo basedo em argumentos HOMO-LUMO para a dureza e moleza, as diferenças de energia FERMO-LUMO descrevem corretamente os sítios duros e moles para os sistemas estudados. Além disso, os orbitais de Kohn-Sham e Hartree-Fock levam às mesmas conclusões.

The FERMO concept was successfully applied to the Pearson's Hard and Soft acid-base principle for four ambidentate ligands. Using an intuitive statement based on the HOMO-LUMO approach to the hardness and softness, the FERMO-LUMO gaps correctly describe the soft and hard sites in the studied systems. Moreover, Kohn-Sham and Hartree-Fock MOs lead to same conclusions.
\end{abstract}

Keywords: HSAB, FERMO, molecular orbitals, HOMO-LUMO

\section{Introduction}

Molecular orbitals (MOs) and their properties, like energies and symmetries, are very useful for chemists. Since Fukui et al. ${ }^{1}$ used the frontier electron density for predicting the most reactive position in $\pi$-electron systems and Hoffmann and Woodward ${ }^{2}$ set out orbital symmetry rules to explain several types of reactions in conjugated systems, the frontier MOs gained importance for the better understanding of chemical reactions. The energy gap between the highest occupied molecular orbital (HOMO) and the lowest unoccupied molecular orbital (LUMO) have been used to explain several chemical phenomena., ${ }^{3,4}$ An example of the HOMO-LUMO approach is the interpretation of hardness $(\eta)$ and softness $(\sigma):{ }^{5}$ hard molecules have a large HOMOLUMO gap and soft molecules have a small gap.

Nevertheless, the HOMO-LUMO approach is not adequate to explain the reactivity for some systems ${ }^{4,6}$ like those formed by ambidentate ligands, such as the thiocyanate anion. This anion has two coordinating sites, a soft one, in which sulfur is the linking atom and a hard one, with nitrogen

* e-mail: figueroa@ime.eb.br as the binding atom. ${ }^{5,7}$ Clearly, the HOMO-LUMO gap itself cannot describe the hardness difference between the two binding sites in the same molecule. The very chemically intuitive Frontier Effective-for-Reaction Molecular Orbital (FERMO) concept $^{6}$ was introduced to solve HOMO-LUMO limitations and better explain the chemical behavior of molecules. In the FERMO concept, MO composition and shape are taken into account to identify the MO that will actually be involved in a given reaction. A molecule could have as many FERMOs as it has reactions sites and it could be the HOMO or any other frontier MO. ${ }^{6}$

\section{Results and Discussion}

In this communication we report a Density Functional Theory (DFT) and Hartree-Fock (HF) study to show how the FERMO concept can be used to explain the hard and soft behavior for the ambidentate ligands: $\mathrm{SCN}^{-}, \mathrm{NO}_{2}^{-}$, $\mathrm{CH}_{3} \mathrm{COCH}_{2}^{-}$and dimethylsulfoxide (DMSO). These ligands were chosen because a large number of their experimental and theoretical studies are available in the literature. ${ }^{7-13}$ All the calculations were carried out with the Gaussian 98 package. ${ }^{14}$ Each compound was fully optimized with the 
DFT method using the B3LYP functional with the $6-31+\mathrm{G}^{*}$ basis set $\left(6-31+\mathrm{G}^{* *}\right.$ for those that contain hydrogen). No imaginary frequencies were found for the optimized geometries and they were used in all subsequent calculations. Single point energy calculations were performed at HF level using the same basis set used for geometry optimizations. MO figures were prepared using the Gaussian View 2.1 package $^{14}$ using a contour value of 0.030. The FERMO choice criteria was made using the MO compositions and shapes. ${ }^{6}$ The MO compositions were calculated as described in the literature by Solomon and coworkers: ${ }^{15}$ The contribution from an atom to a MO is calculated by the summation of the square of the expansion coefficients of the atomic orbitals centered on that atom. Thus, the FERMO for a particular reaction site should be the MO that has the largest contribution from that particular site. However, some restrictions could be imposed by the MO shapes, as it was the case for carboxylate and phenoxide/alkoxide ions. ${ }^{6}$

As described before, in the $\mathrm{SCN}^{-}$anion, there are two reaction sites: the sulfur atom (soft) and the nitrogen atom (hard). According to the FERMO concept, if a molecule has two different reaction sites, there will be two FERMOs, soft molecules have smaller HOMO-LUMO gaps when compared with hard ones, it can be stated that soft reaction sites in a molecule will have a smaller FERMO-LUMO gap than harder ones. Accordingly, the FERMO-LUMO gap for the sulfur atom, should be smaller than the FERMO-LUMO gap for the nitrogen atom in the $\mathrm{SCN}^{-}$ anion; and it is exactly what happens, the sulfur-FERMO has higher energy than the nitrogen-FERMO, making the FERMO-LUMO gap for the sulfur atom smaller. The FERMOs for the $\mathrm{SCN}^{-}$anion are shown in Figure 1.

The FERMOs for $\mathrm{NO}_{2}^{-}, \mathrm{CH}_{3} \mathrm{COCH}_{2}^{-}$and DMSO are shown in Figure 2, ${ }^{16}$ while Table 1 shows the FERMOLUMO energy gaps for the studied compounds.

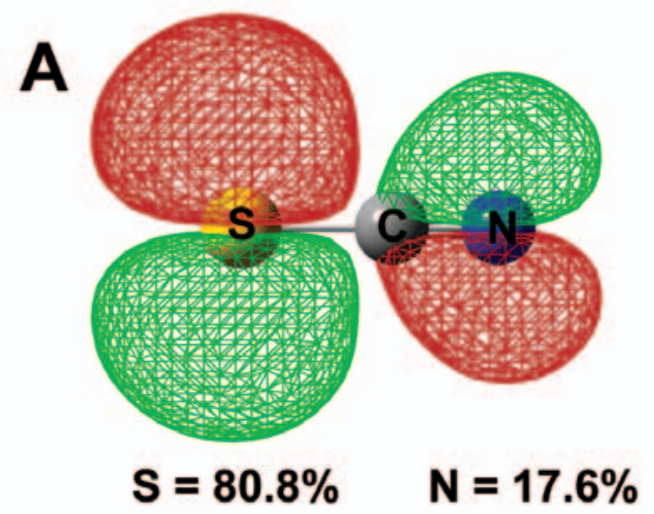
one for each site. Following the Pearson's principle that

Table 1. 1/2 FERMO-LUMO gaps for studied molecules (all values in $\mathrm{eV}$ )

\begin{tabular}{|c|c|c|}
\hline \multirow[t]{2}{*}{ Molecules } & \multicolumn{2}{|c|}{ 1/2 FERMO-LUMO gaps } \\
\hline & DFT & $\mathrm{HF}$ \\
\hline $\mathrm{SCN}^{-}$ & & \\
\hline $\mathrm{S}^{\mathrm{a}}$ & 2.6 & 4.7 \\
\hline $\mathrm{N}^{\mathrm{b}}$ & 4.3 & 7.4 \\
\hline $\mathrm{NO}_{2}^{-}$ & & \\
\hline $\mathrm{N}^{\mathrm{a}}$ & 2.5 & 6.3 \\
\hline $\mathrm{O}^{\mathrm{b}}$ & 3.1 & 7.1 \\
\hline $\begin{array}{l}\mathrm{CH}_{3} \mathrm{COCH}_{2} \\
\mathrm{C} \text { (enolic) })^{\mathrm{a}}\end{array}$ & $3.2^{\mathrm{c}}$ & 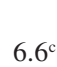 \\
\hline $\mathrm{O}^{\mathrm{b}}$ & $3.6^{\mathrm{c}}$ & $7.7^{\circ}$ \\
\hline DMSO & & \\
\hline$S^{a}$ & 3.2 & 5.9 \\
\hline $\mathrm{O}^{\mathrm{b}}$ & 3.7 & 6.5 \\
\hline
\end{tabular}

${ }^{\text {a }}$ Soft site; ${ }^{\text {b }}$ Hard site; ${ }^{\mathrm{c}}$ Values for $6-31 \mathrm{G}^{* *}$ basis set.

In the nitro-nitrite system, the nitrogen atom is the soft site, as shown by Geerlings and coworkers using the Fukui function. ${ }^{12}$ That behavior is easily explained taking FERMO energies into account. The oxygen atoms equally contribute for their FERMO, as expected due to resonance effects. The FERMO choice for those oxygen atoms was based on the same arguments used previously for carboxylate ions, ${ }^{6}$ as implied by the Isolobal Analogy introduced by Hoffmann. ${ }^{17}$

For the enolate ion, the FERMO-LUMO gaps indicate that the enolic carbon atom is the soft site, as observed before. ${ }^{9,13}$ However, for this anion was observed a strong basis set effect, caused by the diffuse function. This basis set effect leads to an overestimation of the contribution of carbon $4 \mathrm{~s}$ atomic orbital to the $\mathrm{MO}$ and it could make the identification of the FERMOs a difficult task. Since the $4 \mathrm{~s}$ atomic orbital does not play an important role in the chemistry of the carbon atoms, we recalculated the MOs for this anion without the diffuse function, i.e. using the $6-31 \mathrm{G}(\mathrm{d}, \mathrm{p})$ basis set. In spite of this effect in MO composition, the MO shapes were not affected. ${ }^{16}$

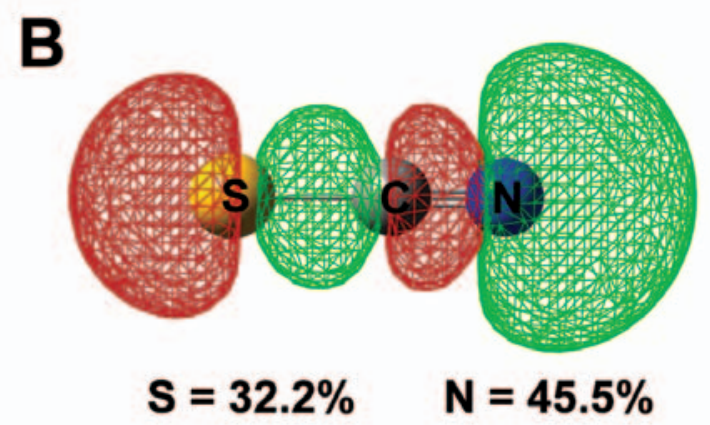

Figure 1. FERMOs for the $\mathrm{SCN}^{-}$anion at $\mathrm{HF}$ level. (A) The sulfur-FERMO and (B) the nitrogen-FERMO. 

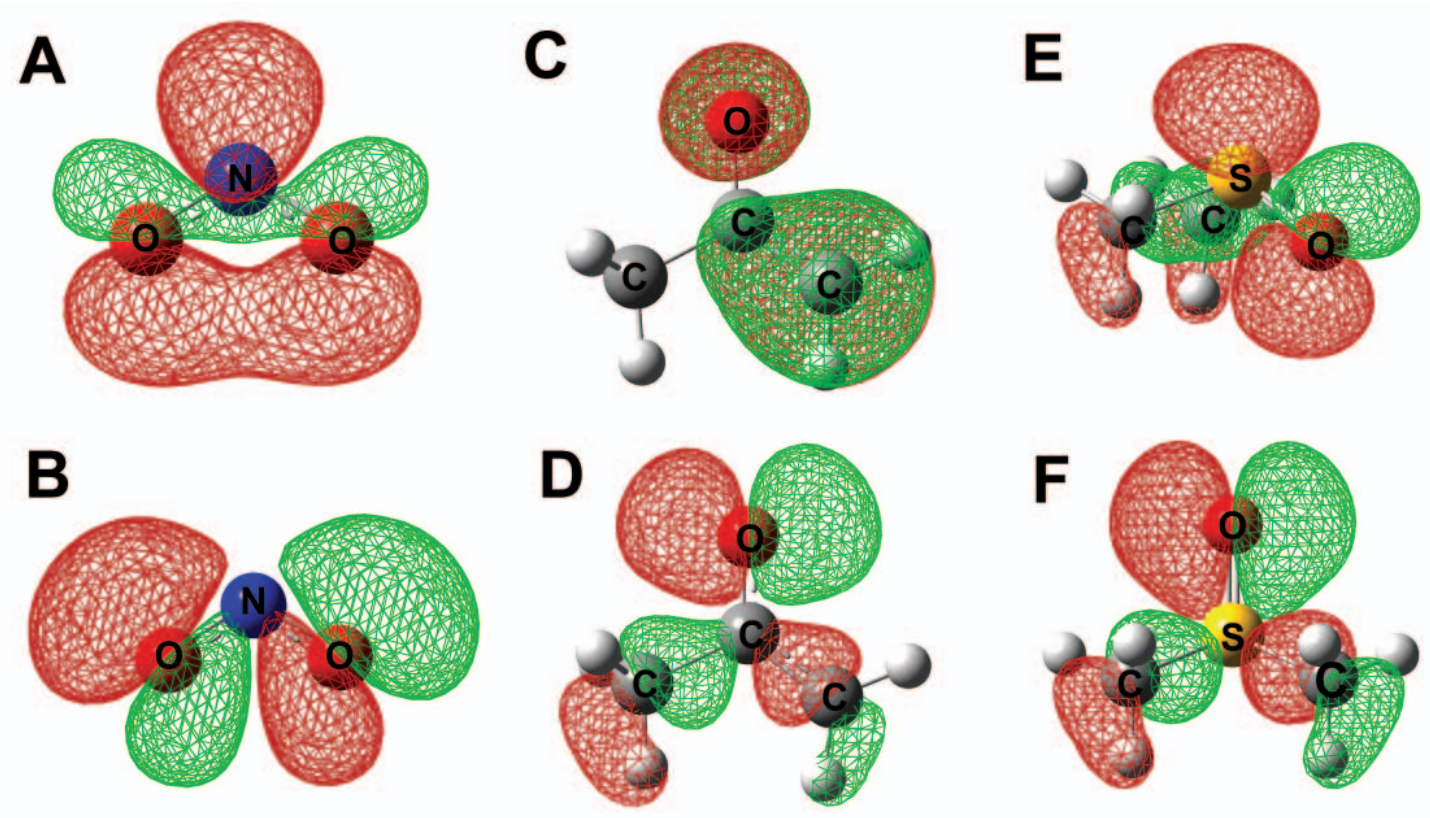

Figure 2. FERMOs for $\mathrm{NO}_{2}^{-}, \mathrm{CH}_{3} \mathrm{COCH}_{2}^{-}$and DMSO. (A) $\mathrm{NO}_{2}^{-}$nitrogen-FERMO; (B) $\mathrm{NO}_{2}^{-}$oxygen-FERMO; (C) $\mathrm{CH}_{3} \mathrm{COCH}_{2}^{-}$carbon-FERMO; (D) $\mathrm{CH}_{3} \mathrm{COCH}_{2}^{-}$oxygen-FERMO; (E) DMSO sulfur-FERMO; (F) DMSO oxygen-FERMO.

The DMSO molecule has the sulfur atom as a soft site and the oxygen atom as a hard site. ${ }^{10}$ Again, the FERMOLUMO hypothesis agrees with the experimental data. An interesting point is that the sulfur-FERMO has also a strong oxygen contribution, being the smallest MO contribution difference between two reacting atoms in all of the studied molecules. ${ }^{16}$ This is probably due to the resonance present in DMSO, which leads to a positive charge on the sulfur, ${ }^{10,11}$ making its electron pair less available and affecting the MO composition.

Since the results shown here are based on MO energies calculated at DFT level, another discussion should be made. At the DFT level, system properties are determined by the total density of the system and not by its wavefunction, $\psi$, as it is the case for the HF procedure. Once MOs are defined as $\psi^{2}$, the DFT cannot hold the MO definition in its formalism. However, DFT MOs, known as Kohn-Sham (KS) MOs, can be obtained by a mathematical procedure and, because of that, some discussions about their physical significance have appeared. ${ }^{18}$ Thus, we carried out HF calculations to observe the behavior of HF MOs.

Our results ${ }^{16}$ using HF MOs were similar to those observed using KS MOs. That is, the hard-soft properties for the studied molecules were the same for DFT and HF FERMOs. The FERMO shapes are roughly the same for HF and DFT MOs but their energies differ significantly, as previously reported in the literature. ${ }^{6,18}$ Nevertheless, these energy differences were not important in the FERMO analysis of the hard-soft nature. This is a great feature of the FERMO approach. As commented before, ${ }^{6}$ no matter what method one will use, whether DFT or HF, the conclusion about chemical behavior should be the same.

Another important point is the correspondence between FERMO shapes and the geometry of these ligands in coordination compounds. Taking $\mathrm{SCN}^{-}$as an example, the sulfur-FERMO shape implies an angular bond with a Lewis acid. On the other hand, the nitrogen-FERMO shape will lead to a linear bond pattern (see Figure 1). These shape-induced geometries are in complete agreement with experimental results, where the $M$-S-C angles are around $90^{\circ}$ and $M-\mathrm{N}-\mathrm{C}$ angles are near to $180^{\circ}$ (where $M$ is a metallic center). ${ }^{7}$ The same is true for $\mathrm{DMSO}^{10}$ and $\mathrm{NO}_{2}^{-}$ complexes, where different linking patterns of the latter could be understood by taking into account the nitrogen and oxygen-FERMO shapes. ${ }^{8}$

\section{Conclusions}

In summary, we have demonstrated that the FERMO concept can be applied to the Pearson's hard and soft principle in a very simple and chemically intuitive way. The use of FERMO-LUMO gaps, instead of HOMOLUMO gaps, to estimate the hardness are adequate, specially for the cases studied here, as HOMO itself cannot describe two different reaction sites in the same molecule. Therefore, the FERMO concept is an alternative way to explain chemical phenomena when HOMO-LUMO 
arguments fail or cannot be applied. Usually, in such cases, the Fukui function is applied. ${ }^{12}$ The FERMO conclusions are the same as those obtained by applying the Fukui Function. The equivalence between the FERMO approach and the Fukui Function shows that the intuitive statement of FERMO interpretation of Pearson's hard and soft principle is quite reliable. Also important is the independence of the results from the calculation method, as both HF and DFT MOs leads to the same FERMOs and conclusions about chemical reactivity.

\section{Supplementary Information}

Complete FERMO-LUMO gaps, MO compositions, MO energy orders and Cartesian coordinates for stationary points are available free of charge as pdf file at http:// jbcs.sbq.org.br

\section{Acknowledgments}

We gratefully acknowledge the financial support given by $\mathrm{CNPq}, \mathrm{CAPES}$ and FAPERJ.

\section{References}

1. Fukui,K.; Yonezawa, T.; Shingu,H.; J. Chem. Phys. 1952, 20, 722; Fukui, K.; Yonezawa,T.; Nagata, C.; Shingu, H.; J. Chem. Phys. 1954, 22, 1433.

2. Woodward, R.B.; Hoffmann, R.; J. Am. Chem. Soc. 1965, 87 , 395; Hoffmann, R.; Woodward, R. B.; J. Am. Chem. Soc. 1965 87, 2046; Woodward, R.B.; Hoffmann, R.; J. Am. Chem. Soc 1965, 87, 2511; Hoffmann, R.; Woodward, R.B.; J. Am. Chem. Soc. 1965, 87, 4388; Hoffmann, R.; Woodward, R.B.; J. Am. Chem. Soc. 1965, 87, 4389.

3. Fujimoto, H.; Hoffmann, R.; J. Phys. Chem. 1974, 78, 1874; Houk, K.N.; Acc. Chem. Res. 1975, 8, 361; Fujimoto, H.; Sugiyama, T.; J. Am. Chem. Soc. 1977, 99, 15.

4. Fukui, K.; Angew. Chem. Int. Ed. 1982, 21, 801.

5. Parr, R.G.; Pearson, R.G.; J. Am. Chem. Soc. 1983, 105, 7512; Pearson, R.G.; J. Am. Chem. Soc. 1986, 108, 6109; Pearson, R.G.; J. Chem. Educ. 1987, 64, 561; Pearson, R.G.; Inorg. Chem. 1988, 27, 734.

6. da Silva, R.R.; Ramalho, T.C.; Santos, J.M.; Figueroa-Villar, J.D.; J. Phys. Chem. A 2006, 110, 1031.
7. Fleisher, E.; Hawkinson, S.; J. Am. Chem. Soc. 1967, 89, 720; Meek, D.W.; Nicpon, P.E.; Meek, V.I.; J. Am. Chem. Soc. 1970, 92, 5351; Lee, J-S.; Titus, D.D.; Ziolo, R.F.; Inorg. Chem. 1977, 16, 2487; Foster, G.E.; Southerington, I.G.; Begley, M.J.; Sowerby, D.B.; J. Chem. Soc. Chem. Commun. 1991, 54.

8. Klanderman, K.A.; Hamilton, W.C.; Bernal, I.; Inorg. Chim. Acta 1977, 23, 117; Jackson, W.G.; McKeon, J.A.; Cortez, S.; Inorg. Chem. 2004, 43, 6249.

9. House, H.O.; Auerbach, R.A.; Gall, M.; Peet, N.P.; J. Org. Chem. 1973, 38, 514

10. Yeh, A.; Scott, N.; Taube, H.; Inorg. Chem. 1982, 21, 2542; Calligaris, M.; Carugo, O.; Coord. Chem. Rev. 1996, 153, 83.

11. Santos, J.M.; da Silva, R.R.; Formiga, A.L.B.; Tinoco, L.W.; Figueroa-Villar, J.D.; Chem. Phys. 2004, 306, 143.

12. Langenaeker, W.; De Proft, F.; Geerlings, P.; J. Mol. Struct. (THEOCHEM) 1996, 362, 175; De Proft, F.; Martin, J.M.L.; Geerlings, P.; Chem. Phys. Lett. 1996, 256, 400; Geerlings, P.; De Proft, F.; Langenaeker, W.; Chem. Rev. 2003, 103, 1793.

13. Fujimoto, H.; Satoh, S.; J. Phys. Chem. 1994, 98, 1436.

14. Frisch, M.J.; Trucks, G.W.; Schlegel, H.B.; Scuseria, G.E.; Robb, M.A.; Cheeseman, J.R.; Zakrzewski, V.G.; Montgomery Jr., J.A.; Stratmann, R.E.; Burant, J.C.; Dapprich, S.; Millam, J.M.; Daniels, A.D.; Kudin, K.N.; Strain, M.C.; Farkas, O.; Tomasi, J.; Barone, V.; Cossi, M.; Cammi, R.; Mennucci, B.; Pomelli, C.; Adamo, C.; Clifford, S.; Ochterski, J.; Petersson, G.A.; Ayala, P.Y.; Cui, Q.; Morokuma, K.; Salvador, P.; Dannenberg, J.J.; Malick, D.K.; Rabuck, A.D.; Raghavachari, K.; Foresman, J.B.; Cioslowski, J.; Ortiz, J.V.; Baboul, A.G.; Stefanov, B.B.; Liu, G.; Liashenko, A.; Piskorz, P.; Komaromi, I.; Gomperts, R.; Martin, R.L.; Fox, D.J.; Keith, T.; Al-Laham, M.A.; Peng, C.Y.; Nanayakkara, A.; Challacombe, M.; Gill, P.M.W.; Johnson, B.; Chen, W.; Wong, M.W.; Andres, J.L.; Gonzalez, C.; Head-Gordon, M.; Replogle, E.S.; Pople, J.A.; Gaussian 98 (Revision A.11), Gaussian, Inc.: Pittsburgh PA, 2001.

15. Chen, P.; Fujisawa, K.; Solomon, E.I.; J. Am. Chem. Soc. 2000 , 122, 10177.

16. See Electronic Supplementary Information for complete results.

17. Hoffmann, R.; Angew. Chem. Int. Ed. 1982, 21, 711.

18. Politzer, P.; Abu-Awwad, F.; Theor. Chem. Acc. 1998, 99, 83; Stowasser, R.; Hoffmann, R.; J. Am. Chem. Soc. 1999, 121, 3414 .

Received: February 16, 2006

Published on the web: March 10, 2006 


\title{
Concerning the FERMO Concept and Pearson's Hard and Soft Acid-Base Principle
}

\author{
Rodrigo R. da Silva, ${ }^{a}$ Joana M. Santos, ${ }^{b}$ Teodorico C. Ramalho ${ }^{c}$ and J. Daniel Figueroa-Villar ${ }^{* a}$ \\ ${ }^{a}$ Departamento de Química, Instituto Militar de Engenharia, Praça General Tibúrcio, 80, 22290-070 \\ Rio de Janeiro-RJ, Brazil \\ ${ }^{b}$ Departamento de Química Geral e Inorgânica, Instituto de Química, Universidade do Estado do Rio de Janeiro, \\ Rua São Francisco Xavier, 524, 20550-013 Rio de Janeiro-RJ, Brazil \\ ${ }^{\mathrm{c}}$ Departamento de Química, Universidade Federal de Lavras, Lavras-MG, Brazil
}

We decide to calculate the FERMO-LUMO gaps using the 6-31G** basis set for all compounds, since we have to used it for the enolate ion for solve MO composition problem (see Table S3). It was observed a shift when the diffuse function is added, but a important feature is that the difference between the hard and soft FERMO-LUMO gaps are constant, independently of the basis set used to calculate the MO energy. The only exception was the enolate ion - as should be expected, since the enolate ion presents an anomalous result with the basis set $6-31+\mathrm{G}^{* *}$. Nevertheless, the variation along the basis set is really small $(0.2 \mathrm{eV}$ in the HF method).

As one can notice, the values between HF and DFT methods are quite different. However, this effect is expected due to MO energy differences.

Table S1. 1/2 FERMO-LUMO gaps for different methods and basis set

\begin{tabular}{lcccc}
\hline & \multicolumn{5}{c}{$\begin{array}{c}1 / 2 \text { FERMO-LUMO gap (eV) } \\
\text { Molecules }\end{array}$} & DFT/6-31+G*-31G** & HF/6-31+G** & HF/6-31G** \\
\hline $\mathrm{SCN}^{-}$ & & & & \\
$\mathrm{S}$ & 2.6 & 3.9 & 4.7 & 7.5 \\
$\mathrm{~N}$ & 4.3 & 5.6 & 7.4 & 10.2 \\
$\mathrm{NO}_{2}^{-}$ & & & & \\
$\mathrm{N}$ & 2.5 & 2.5 & 6.3 & 7.3 \\
$\mathrm{O}$ & 3.1 & 3.1 & 7.1 & 8.1 \\
$\mathrm{CH}_{3} \mathrm{COCH}_{2}^{-}$ & & & & \\
$\mathrm{C}($ enolic) & 1.8 & 3.2 & 3.9 & 6.6 \\
$\mathrm{O}$ & 2.2 & 3.6 & 5.2 & 7.7 \\
$\mathrm{DMSO}$ & & & & \\
$\mathrm{S}$ & 3.2 & 3.6 & 5.9 & 7.5 \\
$\mathrm{O}$ & 3.7 & 4.1 & 6.5 & 8.1 \\
\hline
\end{tabular}

Table S2. MO numeration

\begin{tabular}{lcccc}
\hline Molecules & DFT/6-31+G** & DFT/6-31G** & HF/6-31+G ${ }^{* *}$ & HF/6-31G** \\
\hline SCN $^{-}$ & & & & \\
HOMO & 15 & 15 & 15 & 15 \\
S-FERMO & 15 & 15 & 15 & 15 \\
N-FERMO & 11 & 13 & 11 & 11 \\
$\mathrm{NO}_{2}^{-}$ & & & & \\
HOMO & 12 & 12 & 12 & 12 \\
N-FERMO & 12 & 12 & 12 & 12 \\
O-FERMO & 11 & 11 & 10 & 10 \\
$\mathrm{CH}_{3}$ COCH & - \\
HOMO & 16 & 16 & 16 & 16 \\
C-FERMO & 16 & 16 & 16 & 16 \\
O-FERMO & 15 & 15 & 15 & 15 \\
DMSO & & & & \\
HOMO & 21 & 21 & 21 & 21 \\
S-FERMO & 21 & 21 & 21 & 21 \\
O-FERMO & 20 & 20 & 20 & 20 \\
\hline & & & & \\
\hline
\end{tabular}

* e-mail: figueroa@ime.eb.br 
Table S3. MO compositions. We are displaying the MO compositions for the five last occupied MOs. MO compositions for DFT/6-31+G** and HF/6$31+\mathrm{G}^{* *}$ methodologies. For the enolate ion the MO compositions for the DFT/6-31G** and HF/6-31G** methodologies are also displayed. All MO compositions are in percentage. Atoms in blue are the soft sites and in red the harder ones

\begin{tabular}{|c|c|c|c|c|c|}
\hline & \multicolumn{4}{|c|}{$\begin{array}{l}\text { DFT/6-31+G** } \\
\text { Five last occupied MOs }\end{array}$} & \\
\hline & 11 & 12 & 13 & $14^{\mathrm{a}}$ & $15^{\mathrm{a}}$ \\
\hline $\mathrm{C} 1$ & 20.61 & 44.08 & 44.08 & 1.38 & 1.38 \\
\hline $\mathrm{N} 2$ & 63.07 & 36.61 & 36.61 & 20.76 & 20.76 \\
\hline \multirow[t]{3}{*}{ S3 } & 16.32 & 19.31 & 19.31 & 77.87 & 77.87 \\
\hline & \multicolumn{5}{|c|}{$\begin{array}{c}\mathrm{HF} / 6-31+\mathrm{G}^{* *} \\
\text { Five last occupied MOs }\end{array}$} \\
\hline & 11 & 12 & 13 & $14^{\mathrm{a}}$ & $15^{\mathrm{a}}$ \\
\hline $\mathrm{C} 1$ & 22.27 & 39.24 & 39.24 & 1.71 & 1.71 \\
\hline $\mathrm{N} 2$ & 45.51 & 41.82 & 41.82 & 17.55 & 17.55 \\
\hline S3 & 32.22 & 18.94 & 18.94 & 80.75 & 80.75 \\
\hline \multicolumn{6}{|c|}{ a Degenerated MOs. } \\
\hline \multicolumn{6}{|c|}{$\mathrm{NO}_{2}^{-}$} \\
\hline & \multicolumn{5}{|c|}{$\begin{array}{c}\text { DFT/6-31+G** } \\
\text { Five last occupied MOs }\end{array}$} \\
\hline & 8 & 9 & 10 & 11 & 12 \\
\hline N1 & 47.89 & 48.44 & 0.28 & 1.41 & 52.35 \\
\hline $\mathrm{O} 2$ & 26.13 & 25.84 & 49.80 & 49.26 & 23.82 \\
\hline \multirow[t]{3}{*}{$\mathrm{O} 3$} & 25.98 & 25.72 & 49.93 & 49.34 & 23.84 \\
\hline & \multicolumn{4}{|c|}{$\mathrm{HF} / 6-31+\mathrm{G}^{* *}$} & \\
\hline & 8 & 9 & 10 & 11 & 12 \\
\hline N1 & 25.38 & 36.54 & 1.49 & 0.38 & 46.93 \\
\hline $\mathrm{O} 2$ & 37.27 & 31.81 & 49.20 & 49.73 & 26.52 \\
\hline $\mathrm{O} 3$ & 37.34 & 31.65 & 49.30 & 49.89 & 26.55 \\
\hline
\end{tabular}

\section{$\mathrm{CH}_{3} \mathrm{COCH}_{2}^{-}$}

DFT/6-31+G**

Five last occupied MOs

\begin{tabular}{lccccc}
\hline & 12 & 13 & 14 & 15 & 16 \\
$\mathrm{C} 1$ & 20.56 & 15.31 & 28.23 & 17.88 & 5.84 \\
O2 & 35.78 & 27.41 & 49.40 & 14.77 & 33.06 \\
C3 & 14.17 & 15.09 & 6.62 & $46.91^{\mathrm{a}}$ & 57.39 \\
$\mathrm{H} 4$ & 5.46 & 12.67 & 0.00 & 0.06 & 0.02 \\
$\mathrm{H} 5$ & 0.00 & 11.51 & 0.00 & 0.24 & 0.03 \\
C6 & 10.86 & 15.70 & 6.34 & 19.71 & 0.62 \\
H7 & 2.77 & 1.14 & 4.72 & 0.00 & 1.52 \\
H8 & 7.60 & 0.01 & 0.00 & 0.43 & 0.00 \\
H9 & 2.80 & 1.17 & 4.68 & 0.00 & 1.52
\end{tabular}

${ }^{a}$ The MO composition from $\mathrm{C} 3$ (the enolic carbon atom) is large because the diffuse function creates an anomalous carbon $4 \mathrm{~s}$ contribution. This became clearer when the total contribution from the $\mathrm{C} 3$ atom is splited in terms of its atomic orbitals (AOs). As it can be seem, the $4 \mathrm{~s}$ AO is responsible for more than $85 \%$ of the MO contribution for the C3 AOs. Since the $4 \mathrm{~s} \mathrm{AO}$ is included only when diffuse functions are added into the basis set, this large $4 \mathrm{~s}$ contribution was a basis set effect caused by the diffuse function. To avoid this effect, we were forced to remove the diffuse function, and the FERMOs from $\mathrm{C}$ and $\mathrm{O}$ were better characterized. The effect is present in both HF and DFT calculations.

\begin{tabular}{|c|c|c|c|c|c|c|}
\hline \multicolumn{7}{|c|}{$\mathrm{DFT} / 6-31+\mathrm{G}^{* *}$} \\
\hline \multicolumn{2}{|c|}{ C3 Atomic Orbitals } & \multicolumn{5}{|c|}{ Five last occupied MOs } \\
\hline & & 12 & 13 & 14 & 15 & 16 \\
\hline $1 \mathrm{~S}$ & & 0.32 & 0.00 & 0.00 & 0.08 & 0.00 \\
\hline $2 \mathrm{~S}$ & & 1.43 & 0.01 & 0.00 & 0.37 & 0.00 \\
\hline $2 \mathrm{PX}$ & & 74.49 & 44.88 & 0.00 & 0.63 & 0.00 \\
\hline $2 \mathrm{PY}$ & & 3.22 & 42.45 & 0.00 & 0.81 & 0.00 \\
\hline $2 \mathrm{PZ}$ & & 0.00 & 0.00 & 77.53 & 0.00 & 47.16 \\
\hline $3 \mathrm{~S}$ & & 2.90 & 0.06 & 0.00 & 2.88 & 0.00 \\
\hline $3 \mathrm{PX}$ & & 9.48 & 3.82 & 0.00 & 0.30 & 0.00 \\
\hline 3PY & & 1.29 & 2.33 & 0.00 & 0.30 & 0.00 \\
\hline $3 \mathrm{PZ}$ & & 0.00 & 0.00 & 21.35 & 0.00 & 28.97 \\
\hline $4 S$ & & 4.97 & 0.42 & 0.00 & 88.04 & 0.00 \\
\hline $4 \mathrm{PX}$ & & 1.73 & 2.75 & 0.00 & 3.04 & 0.00 \\
\hline $4 \mathrm{PY}$ & & 0.03 & 2.51 & 0.00 & 3.54 & 0.00 \\
\hline $4 \mathrm{PZ}$ & & 0.00 & 0.00 & 0.77 & 0.00 & 23.85 \\
\hline $5 X X$ & & 0.03 & 0.37 & 0.00 & 0.00 & 0.00 \\
\hline $5 Y Y$ & & 0.00 & 0.37 & 0.00 & 0.00 & 0.00 \\
\hline $5 Z Z$ & & 0.00 & 0.00 & 0.00 & 0.00 & 0.00 \\
\hline $5 X Y$ & & 0.09 & 0.03 & 0.00 & 0.00 & 0.00 \\
\hline $5 \mathrm{XZ}$ & & 0.00 & 0.00 & 0.18 & 0.00 & 0.01 \\
\hline \multirow[t]{4}{*}{$5 \mathrm{YZ}$} & & 0.00 & 0.00 & 0.17 & 0.00 & 0.00 \\
\hline & \multicolumn{6}{|c|}{ DFT/6-31G** } \\
\hline & \multicolumn{6}{|c|}{ Five last occupied MOs } \\
\hline & 12 & 13 & 14 & & 15 & 16 \\
\hline $\mathrm{C} 1$ & 16.38 & 14.70 & 31.6 & & 2.74 & 2.73 \\
\hline $\mathrm{O} 2$ & 25.83 & 40.13 & 47.5 & & 57.62 & 36.29 \\
\hline $\mathrm{C} 3$ & 20.39 & 7.68 & 8.29 & & 11.79 & 54.30 \\
\hline $\mathrm{H} 4$ & 12.25 & 10.16 & 0.00 & & 0.95 & 0.02 \\
\hline H5 & 0.72 & 12.19 & 0.00 & & 1.53 & 0.02 \\
\hline C6 & 10.62 & 13.63 & 4.11 & & 21.36 & 1.71 \\
\hline H7 & 3.87 & 0.37 & 4.17 & & 0.32 & 2.47 \\
\hline H8 & 6.03 & 0.77 & 0.00 & & 3.36 & 0.00 \\
\hline \multirow[t]{4}{*}{ H9 } & 3.92 & 0.37 & 4.14 & & 0.32 & 2.47 \\
\hline & \multicolumn{6}{|c|}{$\mathrm{HF} / 6-31+\mathrm{G}^{* *}$} \\
\hline & \multicolumn{6}{|c|}{ Five last occupied MOs } \\
\hline & 12 & 13 & 14 & & 15 & 16 \\
\hline $\mathrm{C} 1$ & 19.84 & 13.23 & 19.78 & & 16.17 & 6.42 \\
\hline $\mathrm{O} 2$ & 37.77 & 17.75 & 60.3 & & 27.50 & 29.36 \\
\hline $\mathrm{C} 3$ & 9.34 & 25.12 & 5.03 & & $38.11^{\mathrm{a}}$ & 61.00 \\
\hline H4 & 2.20 & 14.27 & 0.00 & & 0.17 & 0.02 \\
\hline H5 & 0.70 & 12.23 & 0.00 & & 0.37 & 0.03 \\
\hline C6 & 13.86 & 13.63 & 6.51 & & 17.00 & 0.32 \\
\hline $\mathrm{H} 7$ & 2.65 & 1.70 & 4.16 & & 0.02 & 1.43 \\
\hline H8 & 10.96 & 0.34 & 0.00 & & 0.64 & 0.00 \\
\hline H9 & 2.68 & 1.74 & 4.13 & & 0.02 & 1.43 \\
\hline
\end{tabular}

${ }^{a}$ Same basis set effect observed for DFT calculations. 
Table S3. Cont.

\begin{tabular}{lccccc}
\hline \multicolumn{5}{c}{ HF/6-31+G** } \\
C3 Atomic Orbitals & \multicolumn{5}{c}{ Five last occupied MOs } \\
\hline & 12 & 13 & 14 & 15 & 16 \\
$1 \mathrm{~S}$ & 0.29 & 0.00 & 0.00 & 0.15 & 0.00 \\
$2 \mathrm{~S}$ & 1.42 & 0.01 & 0.00 & 0.62 & 0.00 \\
$2 \mathrm{PX}$ & 66.39 & 37.81 & 0.00 & 2.05 & 0.00 \\
2PY & 18.70 & 30.93 & 0.00 & 1.96 & 0.00 \\
2PZ & 0.00 & 0.00 & 72.44 & 0.00 & 45.28 \\
$3 \mathrm{~S}$ & 0.07 & 0.04 & 0.00 & 3.76 & 0.00 \\
$3 \mathrm{PX}$ & 9.65 & 9.90 & 0.00 & 0.91 & 0.00 \\
$3 \mathrm{PY}$ & 2.14 & 7.16 & 0.00 & 0.55 & 0.00 \\
$3 \mathrm{PZ}$ & 0.00 & 0.00 & 26.78 & 0.00 & 37.72 \\
$4 \mathrm{~S}$ & 0.09 & 11.35 & 0.00 & 84.24 & 0.00 \\
$4 \mathrm{PX}$ & 0.87 & 0.28 & 0.00 & 2.54 & 0.00 \\
$4 \mathrm{PY}$ & 0.08 & 1.82 & 0.00 & 3.20 & 0.00 \\
$4 \mathrm{PZ}$ & 0.00 & 0.00 & 0.29 & 0.00 & 16.95 \\
$5 \mathrm{XX}$ & 0.00 & 0.32 & 0.00 & 0.00 & 0.00 \\
$5 \mathrm{YY}$ & 0.03 & 0.33 & 0.00 & 0.00 & 0.00 \\
$5 \mathrm{ZZ}$ & 0.00 & 0.00 & 0.00 & 0.00 & 0.00 \\
$5 \mathrm{XY}$ & 0.26 & 0.03 & 0.00 & 0.01 & 0.00 \\
$5 \mathrm{XZ}$ & 0.00 & 0.00 & 0.27 & 0.00 & 0.04 \\
$5 \mathrm{YZ}$ & 0.00 & 0.00 & 0.22 & 0.00 & 0.01 \\
\hline
\end{tabular}

$\mathrm{HF} / 6-31 \mathrm{G}^{* *}$

Five last occupied MOs

\begin{tabular}{lccccc}
\hline & 12 & 13 & 14 & 15 & 16 \\
$\mathrm{C} 1$ & 18.30 & 10.70 & 21.78 & 3.15 & 4.30 \\
$\mathrm{O} 2$ & 39.20 & 23.08 & 59.55 & 64.49 & 31.29 \\
$\mathrm{C} 3$ & 12.48 & 17.58 & 6.28 & 9.48 & 59.67 \\
$\mathrm{H} 4$ & 3.98 & 16.79 & 0.00 & 0.92 & 0.02 \\
$\mathrm{H} 5$ & 0.38 & 15.68 & 0.00 & 1.19 & 0.02 \\
$\mathrm{C} 6$ & 10.08 & 13.42 & 5.28 & 17.79 & 0.85 \\
$\mathrm{H} 7$ & 2.88 & 1.34 & 3.56 & 0.29 & 1.93 \\
$\mathrm{H} 8$ & 9.78 & 0.03 & 0.00 & 2.40 & 0.00 \\
$\mathrm{H} 9$ & 2.92 & 1.37 & 3.53 & 0.29 & 1.93 \\
\hline
\end{tabular}

\section{DMSO}

DFT/6-31+G**

Five last occupied MOs

\begin{tabular}{lccccc}
\hline & 17 & 18 & 19 & 20 & 21 \\
S1 & 38.00 & 21.52 & 48.79 & 3.40 & 40.61 \\
O2 & 38.18 & 4.53 & 34.24 & 63.43 & 36.61 \\
C3 & 8.37 & 22.92 & 3.78 & 14.57 & 10.21 \\
H4 & 1.03 & 0.46 & 3.16 & 0.03 & 0.75 \\
H5 & 0.81 & 12.62 & 0.13 & 0.21 & 0.19 \\
H6 & 1.72 & 0.96 & 1.42 & 1.77 & 0.24 \\
C7 & 8.36 & 22.92 & 3.79 & 14.57 & 10.21 \\
H8 & 0.79 & 12.64 & 0.13 & 0.21 & 0.19 \\
H9 & 1.03 & 0.46 & 3.16 & 0.03 & 0.75 \\
H10 & 1.71 & 0.98 & 1.41 & 1.77 & 0.24 \\
\hline
\end{tabular}

Five last occupied MOs

\begin{tabular}{lccccc}
\hline & 17 & 18 & 19 & 20 & 21 \\
S1 & 38.42 & 22.03 & 39.09 & 6.13 & 44.29 \\
O2 & 37.05 & 10.84 & 44.34 & 61.79 & 36.73 \\
C3 & 8.59 & 21.59 & 3.89 & 13.98 & 8.12 \\
H4 & 1.45 & 0.13 & 2.39 & 0.01 & 1.03 \\
H5 & 0.76 & 10.89 & 0.07 & 0.45 & 0.16 \\
H6 & 1.47 & 0.93 & 1.93 & 1.60 & 0.18 \\
C7 & 8.59 & 21.61 & 3.90 & 13.99 & 8.11 \\
H8 & 0.74 & 10.90 & 0.07 & 0.45 & 0.17 \\
H9 & 1.46 & 0.13 & 2.39 & 0.01 & 1.03 \\
H10 & 1.46 & 0.95 & 1.93 & 1.60 & 0.18 \\
\hline
\end{tabular}

Table S4. Cartesian Coordinates for stationary points

SCN

\begin{tabular}{llll}
\hline $\mathrm{C} 1$ & 0.000000 & 0.000000 & 0.637074 \\
$\mathrm{~N} 2$ & 0.000000 & 0.000000 & 1.819856 \\
$\mathrm{~S} 3$ & 0.000000 & 0.000000 & -1.035090 \\
\hline $\mathrm{NO}_{2}^{-}$ & & & \\
\hline $\mathrm{N} 1$ & 0.013083 & 0.000000 & -0.056588 \\
$\mathrm{O} 2$ & 0.026637 & 0.000000 & 1.207123 \\
$\mathrm{O} 3$ & 1.138074 & 0.000000 & -0.633735 \\
\hline
\end{tabular}

\section{$\mathrm{CH}_{3} \mathrm{COCH}_{2}$}

\begin{tabular}{lccc}
\hline $\mathrm{C} 1$ & 0.015835 & 0.311493 & -0.116499 \\
$\mathrm{O} 2$ & -0.102313 & 0.762312 & 1.073236 \\
$\mathrm{C} 3$ & 1.189027 & 0.083529 & -0.826497 \\
$\mathrm{H} 4$ & 2.155147 & 0.293538 & -0.371974 \\
$\mathrm{H} 5$ & 1.174033 & -0.303325 & -1.842826 \\
$\mathrm{C} 6$ & -1.315617 & -0.013412 & -0.835469 \\
$\mathrm{H} 7$ & -1.934731 & 0.893181 & -0.879033 \\
$\mathrm{H} 8$ & -1.180424 & -0.400820 & -1.854380 \\
$\mathrm{H} 9$ & -1.874434 & -0.752590 & -0.245272 \\
\hline
\end{tabular}

\section{DMSO}

\begin{tabular}{lccc}
\hline S1 & 0.084657 & 0.081765 & 0.222669 \\
O2 & 0.193386 & 0.305735 & 1.721467 \\
C3 & 1.799515 & -0.044133 & -0.422620 \\
H4 & 2.378825 & 0.814872 & -0.073438 \\
H5 & 2.222046 & -0.964763 & -0.015578 \\
H6 & 1.781616 & -0.092847 & -1.515221 \\
C7 & -0.301962 & 1.710572 & -0.531473 \\
H8 & -1.306232 & 1.980598 & -0.199384 \\
H9 & 0.417976 & 2.451125 & -0.172970 \\
H10 & -0.278632 & 1.629359 & -1.621957 \\
\hline
\end{tabular}

